OPEN ACCESS

Edited by:

Louis M. Mansky,

University of Minnesota Twin Cities,

United States

Reviewed by:

Robert Harrod,

Southern Methodist University,

United States

Tiejun Zhao,

Zhejiang Normal University, China

*Correspondence:

Roberto S. Accolla

roberto.accolla@uninsubria.it

Specialty section:

This article was submitted to

Virology,

a section of the journa

Frontiers in Microbiology

Received: 05 February 2019

Accepted: 01 April 2019

Published: 26 April 2019

Citation:

Forlani G, Baratella M, Tedeschi A, Pique $C$, Jacobson $S$ and Accolla $R S$ (2019) HTLV-1 HBZ Protein Resides

Exclusively in the Cytoplasm of Infected Cells in Asymptomatic Carriers and HAM/TSP Patients.

Front. Microbiol. 10:819. doi: 10.3389/fmicb.2019.00819

\section{HTLV-1 HBZ Protein Resides Exclusively in the Cytoplasm of Infected Cells in Asymptomatic Carriers and HAM/TSP Patients}

\author{
Greta Forlani ${ }^{1}$, Marco Baratella ${ }^{1}$, Alessandra Tedeschi', Claudine Pique ${ }^{2}$, \\ Steve Jacobson ${ }^{3}$ and Roberto S. Accolla ${ }^{1 *}$
}

${ }^{1}$ Laboratories of General Pathology and Immunology "Giovanna Tosi," Department of Medicine and Surgery, School of Medicine, University of Insubria, Varese, Italy, ${ }^{2}$ INSERM U1016, CNRS UMR 8104, Université Paris Descartes, Sorbonne Paris Cité, Institut Cochin, Paris, France, ${ }^{3}$ Viral Immunology Section, Neuroimmunology Branch, NINDS/NIH, Bethesda, MD, United States

Human $T$ cell lymphotropic virus type $1(H T L V-1)$ is the causative agent of adult T cell leukemia/lymphoma (ATL) and HTLV-1-associated myelopathy/tropical spastic paraparesis (HAM/TSP) in a subset of infected subjects. Two viral proteins, Tax-1 and HTLV-1 basic leucine zipper factor (HBZ), play important roles in the pathogenesis of both diseases. We recently demonstrated that HBZ, previously considered a nuclear protein, is exclusively localized in the cytoplasm of peripheral blood mononuclear cells (PBMCs) of HAM/TSP patients. Here, the analysis of a larger panel of HAM/TSP cases confirmed that HBZ is a cytoplasmic protein, while Tax-1 preferentially localized in the cytoplasm with fewer speckle-like dots in the nucleus. More importantly, here we report for the first time that HBZ, when expressed in asymptomatic carriers (AC), is also confined in the cytoplasm. Similarly, Tax-1 was preferentially expressed in the cytoplasm in a significant proportion of AC. Interestingly, in both HAM/TSP and AC patients, the expression of HBZ and Tax-1 was rarely found in the same cell. We observed only few cases coexpressing the two oncoprotein in a very limited number of cells. In representative AC and HAM/TSP patients, cells expressing cytoplasmic $\mathrm{HBZ}$ were almost exclusively found in the CD4+ T cell compartment and very rarely in CD8+ T cells. Interestingly, at least in the cases analyzed, the expression of thymociteexpressed molecule involved in selection (THEMIS) is dispensable for the cytoplasmic localization of HBZ in both AC and HAM/TSP. The study of an HTLV-1-immortalized cell line established from an HAM/TSP patient confirmed HBZ as a resident cytoplasmic protein not shuttling between the cytoplasm and nucleus. These results extend our previous observation on the dichotomy of HBZ localization between HAM/TSP and ATL, pointing to the exclusive either cytoplasmic or nuclear localization in the two diseased states, respectively. Moreover, they show a rather selective expression in distinct cells of either HBZ or Tax-1. The unprecedented observation that HBZ is expressed only in 
the cytoplasm in AC strongly suggests a progressive modification of HBZ localization during the disease states associated to HTLV-1 infection. Future studies will clarify whether the distinct HBZ intracellular localization is a marker or a causative event of disease evolution.

Keywords: HTLV-1, HBZ, Tax-1, HAM/TSP, asymptomatic carriers

\section{INTRODUCTION}

Human T-cell leukemia virus type 1 (HTLV-1) is the first discovered human oncogenic retrovirus (Poiesz et al., 1980) and is thought to infect at least $10-15$ million people worldwide. Several HTLV-1 endemic areas exist in the southern part of Japan, the Caribbean, North and South America, Central and West Africa, and foci in Middle East, Australia, and Melanesia (Gessain and Cassar, 2012). HTLV-1 induces clonal proliferation of infected cells to enhance its propagation, since it is transmitted primarily by cell-to-cell contact (Igakura et al., 2003; Pais-Correia et al., 2009; Pique and Jones, 2012; Bangham et al., 2014). It has been reported that an increased number of infected cells is correlated with a higher rate of transmission by breast-feeding ( $\mathrm{Li}$ et al., 2004). HTLV1 is the cause of a severe form of leukemia affecting adult CD4+ T cells (adult T-cell leukemia/lymphoma or ATL) and of a progressive neurological pathology designated HTLV-1associated myelopathy/tropical spastic paraparesis (HAM/TSP), characterized by spastic progressive limb paralysis, sensory dysfunction, and sphincter function defects (Gessain et al., 1985; Osame et al., 1986). Similar to other retroviruses, the HTLV-1 proviral genome has structural genes, gag, pol, and env, coded by the plus strand of the viral genome. HTLV-1 encodes two regulatory genes, tax and rex, and three accessory genes ( $p 12$, $p 13$, and $p 30$ ) in the plus strand of the provirus (Matsuoka and Jeang, 2007). Another regulatory gene, the HTLV-1 bZIP factor $(H B Z)$, is transcribed from the minus strand of the proviral genome (Larocca et al., 1989; Gaudray et al., 2002). It has been demonstrated that the viral proteins Tax-1 and HBZ play important roles in HTLV-1 infectivity as well as growth and survival of leukemic cells (Matsuoka and Jeang, 2011). Tax-1 promotes proviral transcription and tumorigenesis (Grassmann et al., 2005; Tosi et al., 2011; Forlani et al., 2013). However, Tax-1 expression is generally lost in ATL cells while HBZ transcripts are ubiquitously expressed in HTLV-1-infected cells, ATL cells, and peripheral blood mononuclear cells (PBMCs) of HTLV-1-infected individuals (Takeda et al., 2004; Taniguchi et al., 2005; Satou et al., 2006). Moreover, the amount of HBZ transcripts positively correlates with HTLV-1 proviral load (PVL) in asymptomatic carriers (AC), HAM/TSP, and ATL patients (Ma et al., 2016). Therefore, it is likely that other mechanisms are involved in the establishment and persistence of the infection, perhaps involving $\mathrm{HBZ}$. Indeed, $\mathrm{HBZ}$ has been reported to promote growth and proliferation of leukemic cells in vivo and in vitro (Satou et al., 2006; Mitobe et al., 2015). There are three different transcriptional isoforms of HBZ: the unspliced (usHBZ) variant and two alternative spliced forms, SP1 and SP2 (Cavanagh et al., 2006; Murata et al., 2006). The SP1 form occurs more frequently than SP2 (Cavanagh et al., 2006). The sequences of SP1 and usHBZ forms are identical with the exception of the first 7 amino acids and contain 206 amino acids and 209 amino acids, respectively. Although the two protein variants exhibit similar functions (Ma et al., 2016), the spliced form is more abundant than the unspliced form and is found in almost all ATL patients (Usui et al., 2008). All the HBZ protein variants are composed by conserved functional domains: an N-terminal activation domain (AD), a central domain (CD), and a C-terminal basic ZIP domain (bZIP; Gaudray et al., 2002). HBZ displays three nuclear localization signals (NLS) responsible for its nuclear localization (Hivin et al., 2005; Zhao and Matsuoka, 2012) and two functional nuclear export signals (NES) within its N-terminal region (Mukai and Ohshima, 2011), which led us to suppose that HBZ may reside in both cytoplasm and nucleus. Most of the reported subcellular localizations, biochemical interactions, and functional aspects related to HBZ have been assessed in cells overexpressing tagged HBZ. Recently, the availability of the first reported monoclonal antibody (mAb), 4D4-F3, isolated in our laboratory, allowed us to study the expression, localization, and interaction in vivo of endogenous HBZ in HTLV-1-infected ACs, ATL and HAM/TSP patients (Raval et al., 2015; Baratella et al., 2017b). It was found that in chronically infected cell lines and ATL cells, endogenous HBZ interacts and colocalizes with p300 and JunD. Partial colocalization was also observed for CBP and CREB2 (Raval et al., 2015). The amount of HBZ expression in the above cells was 20- to 50-fold less than that found in HBZ-transfected cells (Raval et al., 2015; Shiohama et al., 2016). Subsequent studies have shown that HBZ localizes in different subcellular compartments in ATL and HAM/TSP. While HBZ was found in the nucleus in leukemic cells, with a speckle-like distribution (Raval et al., 2015; Baratella et al., 2017a,b), in HAM/TSP patients, we found for the first time that HBZ localized in the cytoplasm (Baratella et al., 2017b). More recently, a cytoplasmic localization of HBZ in HBZ-transfected T cells was reported (Kinosada et al., 2017), depending on the expression of THEMIS (thymociteexpressed molecule involved in selection), a T-lineage-restricted protein (Brockmeyer et al., 2011; Fu et al., 2013). Interestingly, cytoplasmic HBZ protein was almost selectively found in CD4+ $\mathrm{T}$ cells without relationships with CD25 expression, suggesting that $\mathrm{CD} 4+\mathrm{T}$ cells were either not in rapid proliferation or not included in the classical resting regulatory $\mathrm{T}$ cell compartment (Baratella et al., 2017b). Consistently, it has been previously reported that HBZ-specific humoral immune response correlated with reduced $\mathrm{CD} 4+\mathrm{T}$ cell activation in HAM/TSP patients (Enose-Akahata et al., 2013; Enose-Akahata et al., 2017). The distinct expression patterns of HBZ and Tax-1 in PBMCs of infected AC, ATL, and HAM/TSP patients suggest that Tax-1 and 
HBZ have different roles in the course of HTLV-1 pathogenesis. In the present study, the analysis of a larger panel of patients has added new relevant information on this point. PBMCs from $10 \mathrm{HTLV}-1 \mathrm{AC}$ and $10 \mathrm{HAM} / \mathrm{TSP}$ patients were analyzed. Expression and subcellular distribution of endogenous HBZ and Tax-1 proteins were assessed by confocal microscopy with the 4D4-F3 and A51-2 mAbs, respectively. Consistent with our previous findings, in HAM/TSP, HBZ protein is expressed in a discrete percentage of cells $(2-10 \%$ of total PBMC), and its expression is confined in the cytoplasm. Of particular interest, we now report the unprecedented finding that HBZ is found in 6 out of $10 \mathrm{AC}$ in a limited number of cells (1-4\% of the total PBMC), again with an exclusive cytoplasmic localization. The number of HBZ-positive cells was higher in HAM/TSP compared to AC patients. The coexpression of Tax- 1 and $\mathrm{HBZ}$ at the singlecell level was a very rare event both in HAM/TSP and in AC. At least for the patients analyzed, the expression of THEMIS was found not strictly required for HBZ cytoplasmic localization. Confirming our previous results, in HAM/TSP, HBZ-positive cells mainly resided in the CD4+ T cell compartment. Similar results were found in AC. These findings might shed light on a new molecular basis for a role of $\mathrm{HBZ}$ in the progression of HTLV-1 infection. The unprecedented observation that HBZ is expressed only in the cytoplasm in AC strongly suggests a progressive modification of HBZ localization during the disease states associated to HTLV-1 infection.

\section{MATERIALS AND METHODS}

\section{Ethics Statement}

We obtained PBMCs from HTLV-1 asymptomatic donors and HAM/TSP patients as part of the NIH natural history protocol \# 98-N-0047. All individuals gave written informed consent. The patients' data were analyzed anonymously.

\section{Cells}

HTLV-1-immortalized CB T cells (CB-CD4/HTLV-1; Ozden et al., 2004) were cultured in RPMI supplemented with $10 \%$ fetal calf serum (FCS) and $50 \mathrm{U} / \mathrm{ml} \mathrm{IL-2} \mathrm{(Sigma).} \mathrm{PBMCs} \mathrm{from}$ healthy donors, HTLV-1-infected AC, or HAM/TSP patients were purified by Ficoll-Paque TM PLUS (GE-Healthcare BioScience, Milan, Italy) from heparinated blood. PBMCs from healthy donors were obtained from the Blood Transfusion Center, Ospedale di Circolo, Fondazione Macchi, Varese, whereas PBMCs of AC and HAM/TSP patients were isolated by FicollHypaque (Lonza) centrifugation and cryopreserved in liquid nitrogen until use.

\section{HTLV-1 Proviral Load Measurement}

HTLV-1 PVL was measured using ddPCR (Bio-Rad) as previously described (Brunetto et al., 2014). DNA was extracted from the PBMCs and cerebro-spinal fluid (CSF) cell pellets using a DNeasy Blood and Tissue kit (Qiagen) according to the manufacturer's instructions. DNA was digested with the restriction enzyme BamH1 (New England Biolabs) for $30 \mathrm{~min}$ at $37^{\circ} \mathrm{C}$ and diluted $1: 5$ with PCR-certified water. The digested, diluted DNA was mixed with both HTLV-1 tax and human ribonuclease $\mathrm{P}$ protein subunit 30 (RPP30) primers and probes and Bio-Rad $2 \times$ Supermix and then emulsified with droplet generator oil using a QX-100 droplet generator according to the manufacturer's instructions (Bio-Rad). The following primers and probe were used to amplify and detect a 154-base-pair region of HTLV-1 tax: ddPCR HTLV-1 tax F: 5'-CTTATTTGGACATTTACCGATG-3'; ddPCR HTLV-1 tax R: 5'-TGAGGCCGTGTGAGAGTAGA-3'; ddPCR HTLV-1 tax probe: 6FAM-TGATTTCCGGGCCCTGC-MGBNFQ. The droplets were then transferred to a 96-well reaction plate (Eppendorf) and heat-sealed with pierceable sealing foil sheets (Thermo Fisher Scientific). The duplex PCR amplification was performed in this sealed 96-well plate using a GeneAmp 9700 thermocycler (Applied Biosystems). Following PCR amplification, the 96-well plate was transferred to a QX100 droplet reader (Bio-Rad). For PVL calculation, QuantaSoft software version 1.3.2.0 (Bio-Rad) was used to quantify the copies per microliter of each queried target per well. All samples were tested in duplicate, unless otherwise specified, and PVL is reported as the average of the two measurements. The PVL was calculated using the following formula: PVL $=$ [quantity of HTLV-1 tax/(quantity of RPP30/2)] × 100\%.

\section{Treatments}

CB-CD4/HTLV1 cells cultured on glass coverslips precoated with poly-L-lysine were incubated with $20 \mathrm{nM}$ leptomycin B (LMB; Sigma) or the vehicle methanol for $3 \mathrm{~h}$ at $37^{\circ} \mathrm{C}$, $5 \% \mathrm{CO}_{2}$. Cells were then washed and processed for confocal microscopy analysis by using the following antibodies: antiHBZ 4D4-F3 mAb, anti-Tax-1 mAb (clone 168 A51-2 from the NIH AIDS Research and Reference Reagent Program), and antiRelA rabbit polyclonal antibody (Santa Cruz Biotechnology, CA, United States), followed by the secondary antibodies as specified in the figure legends.

\section{Immunofluorescence, Flow Cytometry, and Confocal Microscopy}

Peripheral blood mononuclear cells from AC, HAM/TSP patients, or normal control individuals, after rapid thawing, were washed with warm RPMI medium and immediately processed for immunofluorescence and flow cytometry analysis or for confocal microscopy, as described (Forlani et al., 2016b). For flow cytometry, the following reagents were used: mouse anti-human HLA class I (clone B9.12); mouse anti-human HLA class II DR (clone D1.12), both revealed by FITClabeled rabbit anti-mouse IgG F(ab')2 antiserum (Sigma, Milan, Italy); FITC mouse anti-human CD3 (clone (UCHT1, BD Pharmingen); FITC mouse anti-human CD4 (clone RPA-T4, BD Pharmingen); PE-Cy5 mouse anti-human CD8a (clone RPAT8; eBioscience, Milan, Italy); PE mouse anti-human CD16 (clone B73.1, eBioscience, Milan, Italy); FITC mouse anti-human CD19 (clone HIB19, BD Pharmingen); and phycoerythrin (PE) mouse anti-human CD25 (clone M-A251, BD Pharmingen). For confocal microscopy, cells were cultured on glass coverslips precoated with poly-L-lysine $(0.2 \mathrm{~g} / \mathrm{ml}$, Sigma) for $5 \mathrm{~h}$. The cells were then washed with $1 \times$ Pipes-Hepes-EGTA-MgSO4 (PHEM) 
buffer, pH 6.9 (60 mM PIPES, 25 mM 4-(2-hydroxyethyl)-1piperazineethanesulfonic acid (HEPES), $10 \mathrm{mM}$ ethylene glycolbis(beta-aminoethyl ether)-N, N, N', N'-tetraacetic acid (EGTA), and $2 \mathrm{mM} \mathrm{MgCl}_{2}$ ), three times, fixed in methanol $7 \mathrm{~min}$ at $-20^{\circ} \mathrm{C}$, and blocked with $1 \%$ bovine serum albumin (BSA) in $1 \times$ PHEM for $1 \mathrm{~h}$ at room temperature (RT). Cells were then stained overnight with anti-HBZ 4D4-F3 mAb, anti-Tax$1 \mathrm{mAb}$ (clone 168 A51-2 from the NIH AIDS Research and Reference Reagent Program), anti-vimentin rabbit polyclonal antibody (Santa Cruz Biotechnology, CA, United States), rabbit anti-CD4 mAb (clone EPR6855, ABCAM), and rabbit antiTHEMIS mAb (clone EPR7353, ABCAM), diluted in PHEM buffer containing $0.5 \%$ BSA. The slides were then washed five times with cold $1 \times$ PHEM and incubated in the dark for $2 \mathrm{~h}$ at RT with the following secondary antibodies from Life Technology (Waltham, MA, United States): goat anti-mouse IgG1 coupled to Alexa Fluor 546 to detect HBZ, goat antimouse IgG2a conjugated to Alexa Fluor 488 to detect Tax-1, and goat anti-rabbit IgG conjugated to Alexa Fluor 488 or to Alexa Fluor 546 to detect vimentin, CD4, or THEMIS. For costaining with directly labeled antibodies, after extensive washing with $1 \times$ PHEM, anti-CD8 rabbit $\mathrm{mAb}$ directly conjugated to Alexa Fluor 647 (clone EP1150Y, ABCAM) and mouse anti-human CD25 mAb directly conjugated to Alexa Fluor 488 (clone BC96, BioLegend) were added after the indirect immunofluorescence for $2 \mathrm{~h}$ at RT. Similarly, after indirect immunofluorescence, the nuclei were stained by incubating the cells with DRAQ5 Fluorescent Probe (Thermo Fisher Scientific, Waltham, MA, United States) for $30 \mathrm{~min}$ at RT. CIB-CD4/HTLV1 cells were cultured on glass coverslips precoated with poly-Llysine for $5 \mathrm{~h}$ and processed for confocal microscopy analysis as described above.

After washing, the slides were mounted on coverslips with the Fluor Save reagent [Calbiochem, Vimodrone (MI), Italy] and examined by a confocal laser scanning microscope (Leica TCS SP5; HCX PL APO objective lenses, $63 \times$ original magnification, numerical aperture 1.25). Images were acquired and analyzed by LAS AF Lite Image (Leica Microsystems, Milan, Italy) and/or Fiji (ImageJ) software.

\section{Preparation of Nuclear and Cytoplasmic Extracts and Immunoprecipitation Procedures}

Endogenous HBZ protein was precipitated from both the nuclear and cytoplasmic protein fractions prepared from $8 \times 10^{6} \mathrm{CD}$ CD4/HTLV-1 cells, using an NE-PER Nuclear Cytoplasmic Extraction Reagent kit (Thermo Fisher Scientific) according to the manufacturer's instruction. Briefly, cells were washed twice with cold phosphate buffer saline (PBS) and centrifuged at $500 \mathrm{~g}$ for $3 \mathrm{~min}$. The cell pellet was suspended in $200 \mu \mathrm{l}$ of cytoplasmic extraction reagent I (CERI), supplemented with $0.1 \%$ protease inhibitor cocktail (Sigma), by vortexing. The suspension was incubated on ice for $10 \mathrm{~min}$ followed by the addition of $11 \mu \mathrm{l}$ of a second cytoplasmic extraction reagent II (CERII), vortexed for $5 \mathrm{~s}$, incubated on ice for $1 \mathrm{~min}$, and centrifuged for $5 \mathrm{~min}$ at $16,000 \mathrm{~g}$. The supernatant fraction (cytoplasmic extract) was transferred to a pre-chilled tube. The insoluble pellet fraction, which contains crude nuclei, was resuspended in $100 \mu \mathrm{l}$ of nuclear extraction reagent (NER), supplemented with $0.1 \%$ protease inhibitor cocktail (Sigma), by vortexing for $15 \mathrm{~s}$, incubated on ice for $40 \mathrm{~min}$, and then centrifuged for $10 \mathrm{~min}$ at $16,000 \mathrm{~g}$. Both the nuclear and cytoplasmic protein extracts were used for the subsequent immunoprecipitation experiments.

After preclearing with protein A/G-Sepharose beads, the nuclear and cytoplasmic extracts were incubated with anti-HBZ 4D4-F3 mAb for $1 \mathrm{~h}$ on ice and then immunoprecipitated with protein A/G-Sepharose beads overnight at $4^{\circ} \mathrm{C}$, under rotation. The precipitated proteins were resolved on $9 \%$ sodium dodecyl sulfate-polyacrilamide gel electrophoresis (SDS-PAGE) and analyzed by Western blotting with the anti-HBZ 4D4F3 mAb, followed by Mouse True Blot ULTRA-anti mouse Ig HRP (e Bioscience). This specific secondary antibody was used to avoid the detection of both heavy and light chains in the precipitated proteins. Ten percent of the nuclear and cytoplasmic protein extracts were analyzed by Western blotting with anti Nup98 (Cell Signaling Technology) and anti- $\beta$-tubulin (Sigma) $\mathrm{mAbs}$ to assess the purity of nuclear and cytoplasmic protein extracts, respectively.

\section{RESULTS}

\section{PBMCs of HTLV-1-Positive Asymptomatic Carriers Express HBZ Protein in the Cytoplasm}

By analyzing the subcellular distribution of endogenous HBZ in PBMCs of four HAM/TSP patients, we previously demonstrated for the first time that HBZ is a cytoplasmic protein expressed in a discrete percentage, up to $11 \%$, of the cells. Unlike HAM/TSP, we were unable to detect HBZ-positive cells in PBMCs of four AC (Baratella et al., 2017a,b). To better understand the role of HTLV-1 HBZ protein in the progression of HTLV1 -associated diseases, we extended our previous study to include more HAM/TSP and AC patients. We first analyzed by immunofluorescence and confocal microscopy the subcellular localization of both endogenous HBZ and Tax-1 oncoproteins in PBMCs isolated from $10 \mathrm{HTLV}$-1-positive AC (Table 1). Interestingly, although PBMC from four ACs were negative for HBZ expression, six ACs clearly expressed HBZ protein in 1-4\% of their PBMCs (Table 1). More importantly, HBZ was found localized exclusively in the cytoplasm (Figure 1, HBZ). Parallel staining with vimentin, a cytoplasmic marker, and DRAQ5, a nuclear marker, confirmed HBZ cytoplasmic localization without detectable nuclear colocalization (Figure 1, upper panels). Like $\mathrm{HAM}$ /TSP patients, in PBMCs from AC, cytoplasmic HBZ appeared distributed in dots, sometimes dispersed all over the cytoplasm or concentrated in restricted areas. The expression and the subcellular distribution of Tax-1 were then analyzed. Tax-1 was expressed in $70 \%$ of ACs in a discrete proportion of cells (between 2 and $9 \%$ of total PBMCs). Tax-1 was preferentially localized in the cytoplasm, with fewer speckle-like dots in the nucleus (Figure 1, Tax-1). Co-staining with vimentin and 
TABLE 1 | Percent distribution of HBZ+ and Tax-1+ PBMCs in HTLV-associated pathologies.

\begin{tabular}{|c|c|c|c|c|c|}
\hline Patient & $\begin{array}{c}\text { Proviral } \\
\text { load }\end{array}$ & Pathology & $\begin{array}{c}\text { Total } \\
\text { HBZ+ } \\
\text { cells (\%) }\end{array}$ & $\begin{array}{c}\text { Total } \\
\text { Tax-1+ } \\
\text { cells (\%) }\end{array}$ & $\begin{array}{c}\text { HBZ+ } \\
\text { Tax-1+ } \\
\text { cells (\%) }\end{array}$ \\
\hline $\mathrm{PH} 70$ & 3.26 & $\mathrm{AC}^{*}$ & 1 & 0 & 0 \\
\hline PH928 & 1.02 & $\mathrm{AC}$ & 0 & 3 & 0 \\
\hline PH1152 & 6.43 & $\mathrm{AC}$ & 0 & 2 & 0 \\
\hline $\mathrm{PH} 1186$ & 0 & $\mathrm{AC}$ & 0 & 4 & 0 \\
\hline PH1307 & 8 & $\mathrm{AC}$ & 3 & 4 & 0 \\
\hline $\mathrm{PH} 1320$ & 0 & $\mathrm{AC}$ & 2 & 9 & 0.2 \\
\hline PH1339 & 1.1 & $\mathrm{AC}$ & 4 & 7 & 1 \\
\hline $\mathrm{PH} 1443$ & 2.81 & $\mathrm{AC}$ & 1 & 2 & 0 \\
\hline $\mathrm{PH} 2113$ & 0.58 & $A C$ & 0 & 0 & 0 \\
\hline $\mathrm{PH} 2116$ & 19.16 & $\mathrm{AC}$ & 2 & 0 & 0 \\
\hline PH667 & 8.84 & $\mathrm{HAM} / \mathrm{TSP}$ & 0 & 11 & 0 \\
\hline PH1026 & 27.21 & $\mathrm{HAM} / \mathrm{TSP}$ & 6 & 3 & 0 \\
\hline PH12O5 & 9.99 & $\mathrm{HAM} / \mathrm{TSP}$ & 7 & 2 & 0 \\
\hline $\mathrm{PH} 1216$ & 0.74 & $\mathrm{HAM} / \mathrm{TSP}$ & 8 & 15 & 1 \\
\hline PH1419 & 6.69 & $\mathrm{HAM} / \mathrm{TSP}$ & 4 & 7 & 0 \\
\hline PH1509 & 5.09 & $\mathrm{HAM} / \mathrm{TSP}$ & 10 & 2 & 0 \\
\hline PH1510 & 16.59 & $\mathrm{HAM} / \mathrm{TSP}$ & 2 & 4 & 0 \\
\hline PH2163 & 20.13 & $\mathrm{HAM} / \mathrm{TSP}$ & 1 & 12 & 0 \\
\hline $\mathrm{PH} 2176$ & 27.44 & $\mathrm{HAM} / \mathrm{TSP}$ & 1 & 5 & 0 \\
\hline PH2262 & 20.44 & $\mathrm{HAM} / \mathrm{TSP}$ & 2 & 3 & 0 \\
\hline
\end{tabular}

*AC, asymptomatic carriers.

DRAQ5 showed the Tax-1 prominent cytoplasmic localization (Figure 1, bottom panels).

Interestingly, expression of both HBZ and Tax-1 was found in PBMCs of only four ACs, but in two ACs coexpression of HBZ and Tax-1 within the same cell was detected in a small proportion of cells ( 0.2 or $1 \%$ of total PBMCs; Table 1, PH1320 and PH1339, respectively), indicating that, in $\mathrm{AC}$, the coexpression of the two viral proteins in the same cell is a rare event. A clear example was the PH1339 AC, whose PBMCs were 4 and 7\% positive for HBZ and Tax-1, respectively (Figures $\mathbf{2 a}, \mathbf{b}$, respectively and Figure 2d) while only $1 \%$ coexpressed the two viral proteins (Figures 2f,g, respectively). In coexpressing cells, HBZ did not colocalize with Tax-1 (Figure 2i). Moreover, HBZ was confined in a specific region of the cytoplasm (Figure 2f), while Tax-1 was observed in the nucleus and in the cytoplasm surrounding the HBZ-positive staining (Figure 2g). DRAQ5 was used to stain the nuclei (Figures 2c,h). Differential interference contrast (DIC) images of the cells are shown (Figures 2e,j).

In addition, in $\mathrm{AC} \mathrm{PH} 70$ and $\mathrm{PH} 2116, \mathrm{HBZ}$ was expressed in 1 and $2 \%$ of total PBMC, respectively, while Tax-1 was not detected. On the contrary, in AC PH928, PH1152, and PH1186, HBZ was undetectable, while Tax-1 was found in 3, 2, and $4 \%$ of total PBMCs, respectively. We were unable to detect both HBZ and Tax-1 in patient PH2113 (Table 1). Collectively, these findings demonstrate for the first time that $\mathrm{HBZ}$ protein has a cytoplasmic localization in AC and this localization is maintained in HAM/TSP patients.

\section{HAM/TSP Pathology Is Characterized by a Relevant Increase in Number of HBZ-Positive Cells With an Exclusive Cytoplasmic Localization}

To expand our previous studies in HAM/TSP patients, PBMCs of 10 additional patients were investigated by immunofluorescence and confocal microscopy. Consistent with our previous findings, nine HAM/TSP patients expressed HBZ with a percentage of HBZ-positive cells ranging between 1 and 10\% (Table 1). Interestingly, the number of HBZ-positive cells was higher in

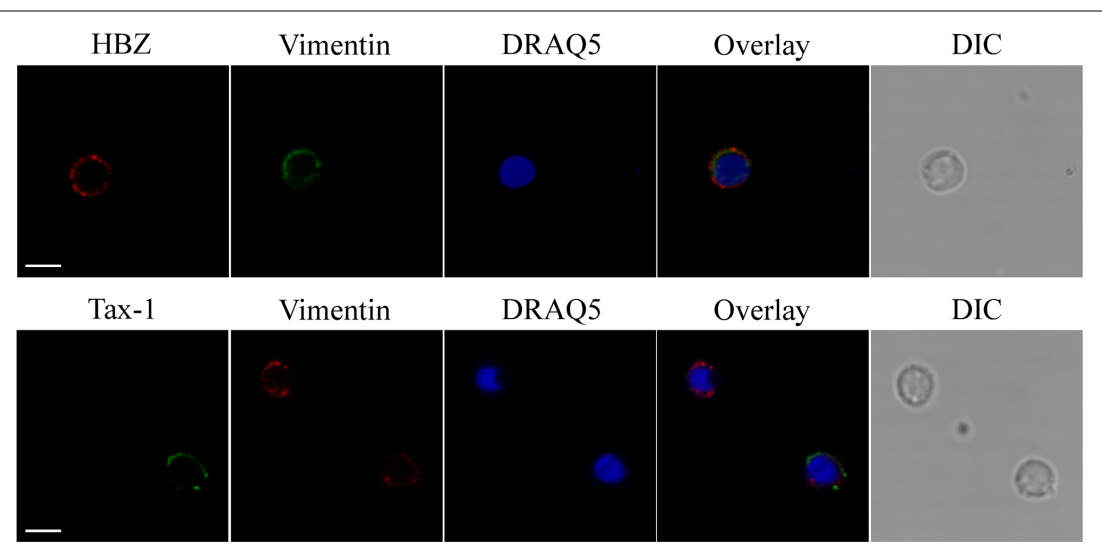

FIGURE 1 | Endogenous HBZ localized in the cytoplasm whereas Tax-1 was distributed both in the nucleus and in the cytoplasm in peripheral blood mononuclear cells (PBMCs) of representative AC PH1307. PBMCs of representative AC PH1307 patient were stained with the 4D4-F3 anti-HBZ monoclonal antibody (mAb) followed by Alexa Fluor 546-conjugated goat anti-mouse IgG1 antibody (red, upper panels) and with the A51-2 anti-Tax-1 mAb followed by Alexa Fluor 488-conjugated goat-anti-mouse IgG2a antibody (green, lower panels) and analyzed by confocal microscopy. Specific counterstaining of nucleus or cytoplasmic compartments was performed by using DRAQ5 fluorescence probe to detect the nucleus (blue) and anti-vimentin rabbit polyclonal antibody followed by goat anti-rabbit IgG conjugated to Alexa Fluor 488 (green, upper panels) or to Alexa Fluor 546 (red, lower panels) to stain the cytoplasmic compartment. DIC represents the differential interference contrast image. At least 300 cells were analyzed. One representative image of single confocal section for HBZ or Tax-1 staining is shown. All scale bars are $5 \mu \mathrm{m}$. 


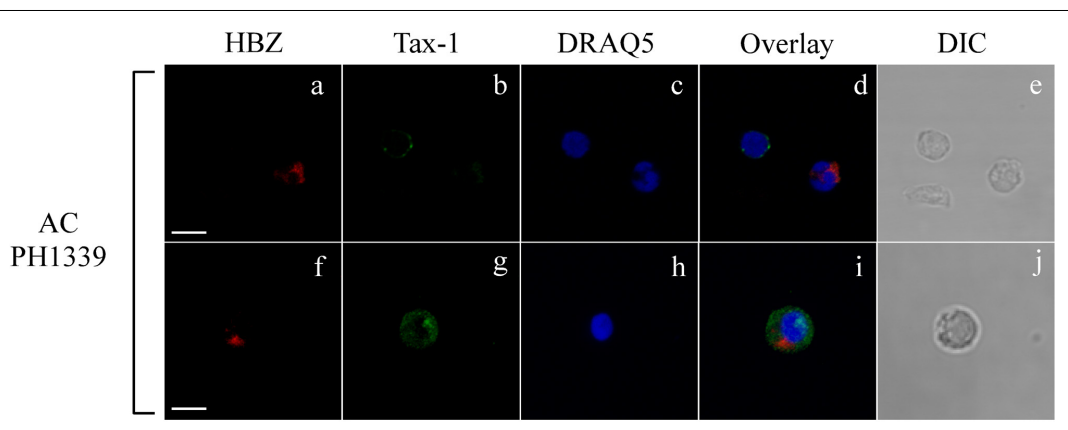

FIGURE 2 | Coexpression of HBZ and Tax-1 in the same cell is a rare event in asymptomatic carriers. PBMCs of representative AC PH1339 patient were co-stained with the 4D4-F3 anti-HBZ mAb followed by Alexa Fluor 546-conjugated goat anti-mouse lgG1 antibody (red, a,f,d,i) and with the A51-2 anti-Tax-1 mAb followed by Alexa Fluor 488-conjugated goat-anti-mouse IgG2a antibody (green, b,g,d,i) and analyzed by confocal microscopy. DRAQ5 fluorescence probe was used to detect the nucleus (c,h,d,i). DIC represents the differential interference contrast image (e,j). At least 300 cells were analyzed. In the top panel, one representative image of single confocal section is shown; in the bottom panel, one representative image derived from the same sample and obtained from the sum of all z-stacks is shown. All scale bars are $5 \mu \mathrm{m}$.

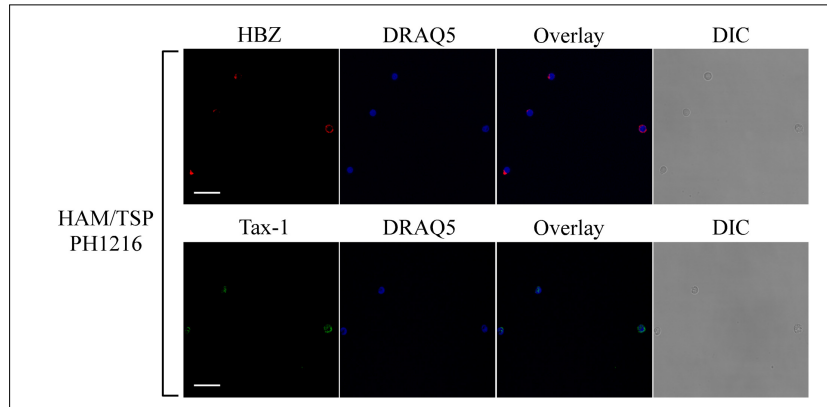

FIGURE 3 | Subcellular localization of endogenous HBZ and Tax-1 in PBMCs of representative HAM/TSP PH1216 patient. (Top panels) PBMCs of representative HAM/TSP patient $\mathrm{PH} 1216$ were stained with the 4D4-F3 anti-HBZ mAb followed by Alexa Fluor 546-conjugated goat anti-mouse lgG1 antibody (red) and (Bottom panels) with the A51-2 anti-Tax-1 mAb followed by Alexa Fluor 488-conjugated goat-anti-mouse IgG2a antibody (green) and analyzed by confocal microscopy. Nucleus was stained with DRAQ5. DIC represents the differential interference contrast image. At least 300 cells were analyzed; two representative fields for HBZ or Tax-1 staining are shown. All scale bars are $5 \mu \mathrm{m}$.

HAM/TSP patients as compared to AC. As clearly shown for a representative patient $\mathrm{PH} 1216$ having $8 \%$ of $\mathrm{HBZ}$-positive cells, the viral protein localized in the cytoplasm with a speckled-like distribution dispersed along the cytoplasm or accumulated in a discrete and limited region of it (Figure 3, HBZ). Parallel staining with DRAQ5 confirmed the HBZ cytoplasmic distribution (Figure 3, top panels, overlay). Tax-1 was expressed in all HAM/TSP patients with a percentage of Tax-1-positive cells ranging between 2 and 15\% of total PBMCs depending on the patient analyzed (Table 1). Patient PH667 did not show any positivity for HBZ, although it expressed Tax-1 in a considerable number of cells (11\%; Table $\mathbf{1})$.

Tax-1 was expressed mostly as discrete dots localized preferentially in the cytoplasm with fewer dots in the nucleus (representative patient PH1216; Figure 3, Tax-1). In this patient, expressing the highest number of $\mathrm{HBZ}$ and Tax-1 positive cells, 8 and $15 \%$, respectively (see Table 1), most cells expressed either
HBZ or Tax-1 (Figure 4, upper panels), with only $1 \%$ of the cells coexpressing the two viral proteins. In some cells, HBZ partially colocalized with Tax-1 in the cytoplasm (Figure 4, bottom panels, overlay).

Thus, as we observed for AC, in HAM/TSP patients, coexpression of HBZ and Tax-1 oncoproteins is a rare event. Importantly, the cumulatively higher number of HBZ- and Tax1-expressing cells in HAM/TSP patients compared to HTLV1-infected AC strongly suggests that evolution toward the neuroinflammatory disease modifies only the number of HBZand Tax-1-positive cells but not the HBZ- or the Tax-1-specific intracellular localization. Moreover, the higher number of HBZand Tax-1-expressing cells in HAM/TSP compared to AC correlated generally, but not always, with higher PVL (Table 1).

\section{CD4+ T Cell Subpopulation Represents the Majority of HBZ-Positive Cells in Asymptomatic Carriers and in HAM/TSP Patients}

We previously demonstrated that in HAM/TSP patients, cytoplasmic HBZ is almost exclusively found in CD4+ T cells not coexpressing the CD25 marker (Baratella et al., 2017b). In order to identify the cell subpopulations expressing the cytoplasmic HBZ protein in AC patients and extend the analysis to the new HAM/TSP patients, we first analyzed by immunofluorescence and flow cytometry the cell surface phenotype of PBMCs of all $\mathrm{AC}$ and HAM/TSP patients.

Peripheral blood mononuclear cells of AC and HAM/TSP patients displayed a phenotype similar to that of PBMCs from healthy donors (Figure 5, representative AC PH1339 and representative HAM/TSP PH1509). PH1339 expressed CD3, CD4, and CD8 markers in 61, 44, and $18 \%$ of PBMCs, respectively. $\mathrm{CD} 3$ and $\mathrm{CD} 4 \mathrm{~T}$ cell markers were expressed in a comparable number of cells in patient HAM/TSP PH1509 (70 and 33\%, respectively) while cells expressing the CD8 marker were increased to $40 \%$. In the sample analyzed, the CD25 marker was undetectable. The CD19-positive B cells were 


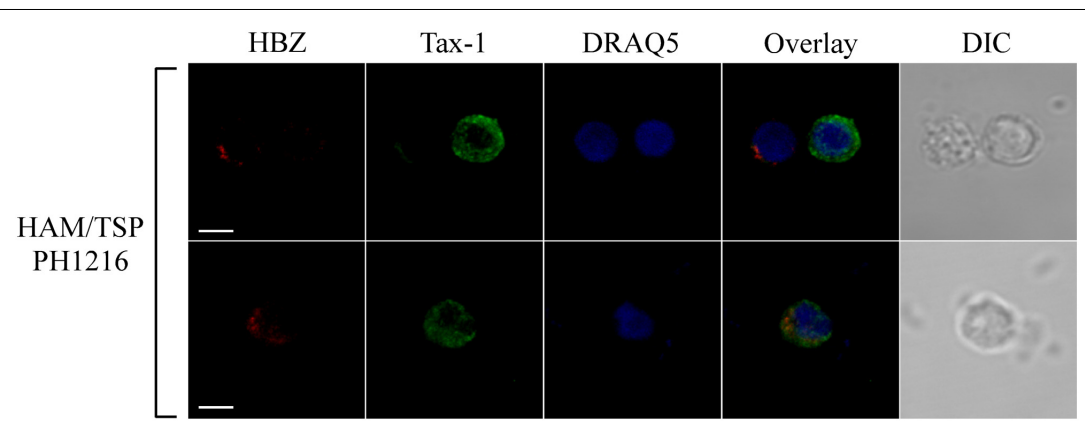

FIGURE 4 | HBZ and Tax-1 were coexpressed at the single-cell level in 1\% of total PBMCs of HAM/TSP representative patient PH1216. PBMCs of representative HAM/TSP PH1216 patient were co-stained with the 4D4-F3 anti-HBZ mAb followed by Alexa Fluor 546-conjugated goat anti-mouse IgG1 antibody (red) and with the A51-2 anti-Tax-1 mAb followed by Alexa Fluor 488-conjugated goat-anti-mouse IgG2a antibody (green) and analyzed by confocal microscopy. DRAQ5 fluorescence probe was used to detect the nucleus. DIC represents the differential interference contrast image. At least 300 cells were analyzed; representative images for HBZ and Tax-1 co-staining are shown. All scale bars are $5 \mu \mathrm{m}$.

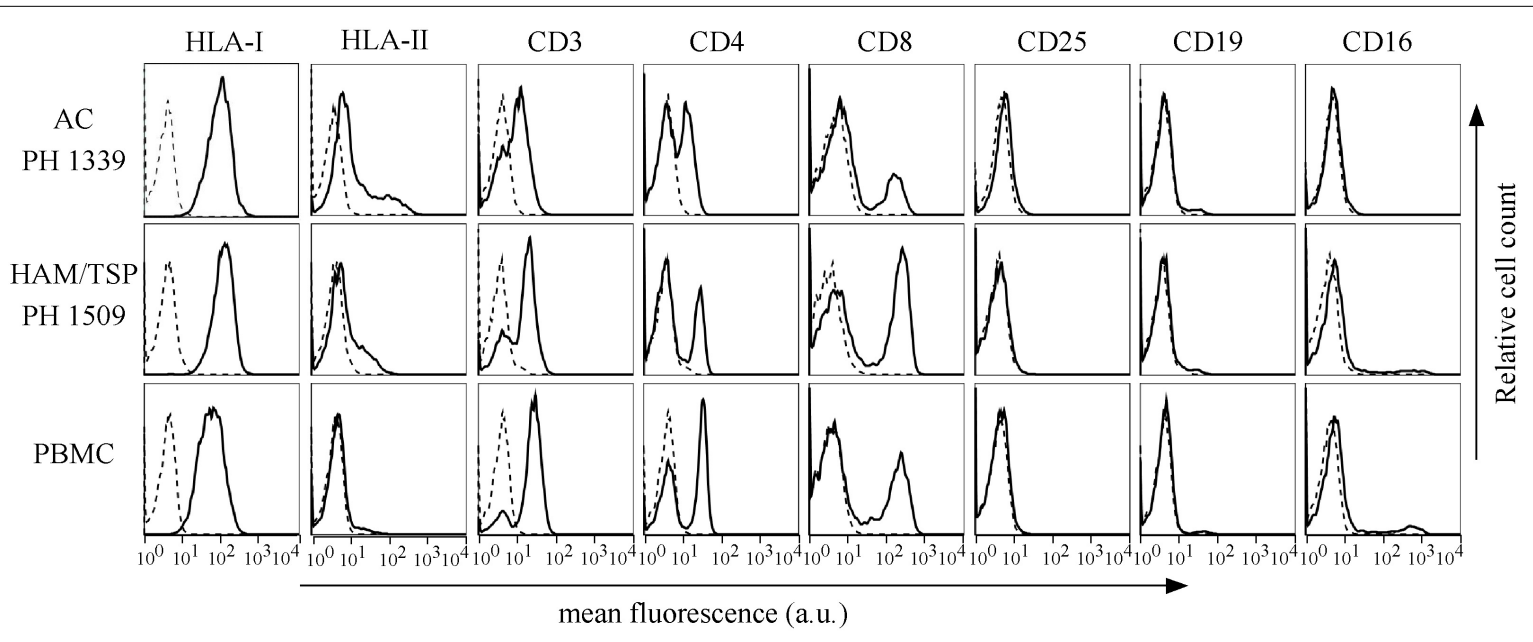

FIGURE 5 | Expression of cells surface markers in PBMCs of AC PH1339, HAM/TSP patient PH1509, and healthy control. The expression of HLA class I, HLA class II DR, CD3, CD4, CD8, CD25, CD19, and CD16 surface molecules on PBMCs from AC PH1339, HAM/TSP patient PH1509, and a healthy control was assessed by immunofluorescence and flow cytometry with antibodies specific for the various markers. Results are expressed as relative number of cells (ordinate) versus the mean intensity of fluorescence in arbitrary units (abscissa). In each histogram, negative controls, obtained by staining the cells with an appropriate isotype-matched antibody, are depicted as a dashed line.

present in almost equal proportions of PH1307 (4.5\%), PH1419 (4.7\%), and normal (3.4\%) PBMCs. NK cells, as assessed by the CD16 marker, were not detected in PH1307, whereas they represented 11.4 and $10 \%$ of $\mathrm{PH} 1419$ and normal PBMCs, respectively. HLA-I was expressed in $100 \%$ of PBMCs of the patients and the normal donor, and HLA class II was expressed in 17, 12, and 9\% of PH1339, PH1509, and normal PBMCs, respectively. Subsequently, we co-stained PBMCs of $\mathrm{AC}$ and HAM/TSP patients for either CD4 or CD8 and HBZ, and we analyzed them by confocal microscopy. Representative data obtained from PBMCs of PH1339 AC and PH1509 HAM/TSP patient revealed a higher number of HBZ-positive cells (7 and 10\%, respectively).

Almost all HBZ-positive cells expressed CD4 (Figure 6A, upper panels). Conversely, HBZ-expressing cells were very rarely detected in the $\mathrm{CD} 8+\mathrm{T}$ cell compartment (Figure 6A, lower panels).
Similarly to AC patients and confirming our previous findings (Baratella et al., 2017b) in HAM/TSP PH1509 patient, cells expressing cytoplasmic HBZ were almost exclusively found in the CD4+ T cells compartment (Figure 6B, top panels) and very rarely, less than 1\%, in CD8+ T cells (Figure 6B, lower panels). From the above data, we conclude that in AC and HAM/TSP patients, cytoplasmic HBZ is almost exclusively expressed in CD4+/CD25- T cells.

\section{The Expression of THEMIS Is Dispensable for the Cytoplasmic Localization of HBZ in Asymptomatic Carriers and HAM/TSP Patients}

Recently, it has been reported that the HBZ-transfected Jurkat $\mathrm{T}$ cell line may partially segregate $\mathrm{HBZ}$ in the cytoplasm as a result of interaction with THEMIS (Kinosada et al., 2017), a 


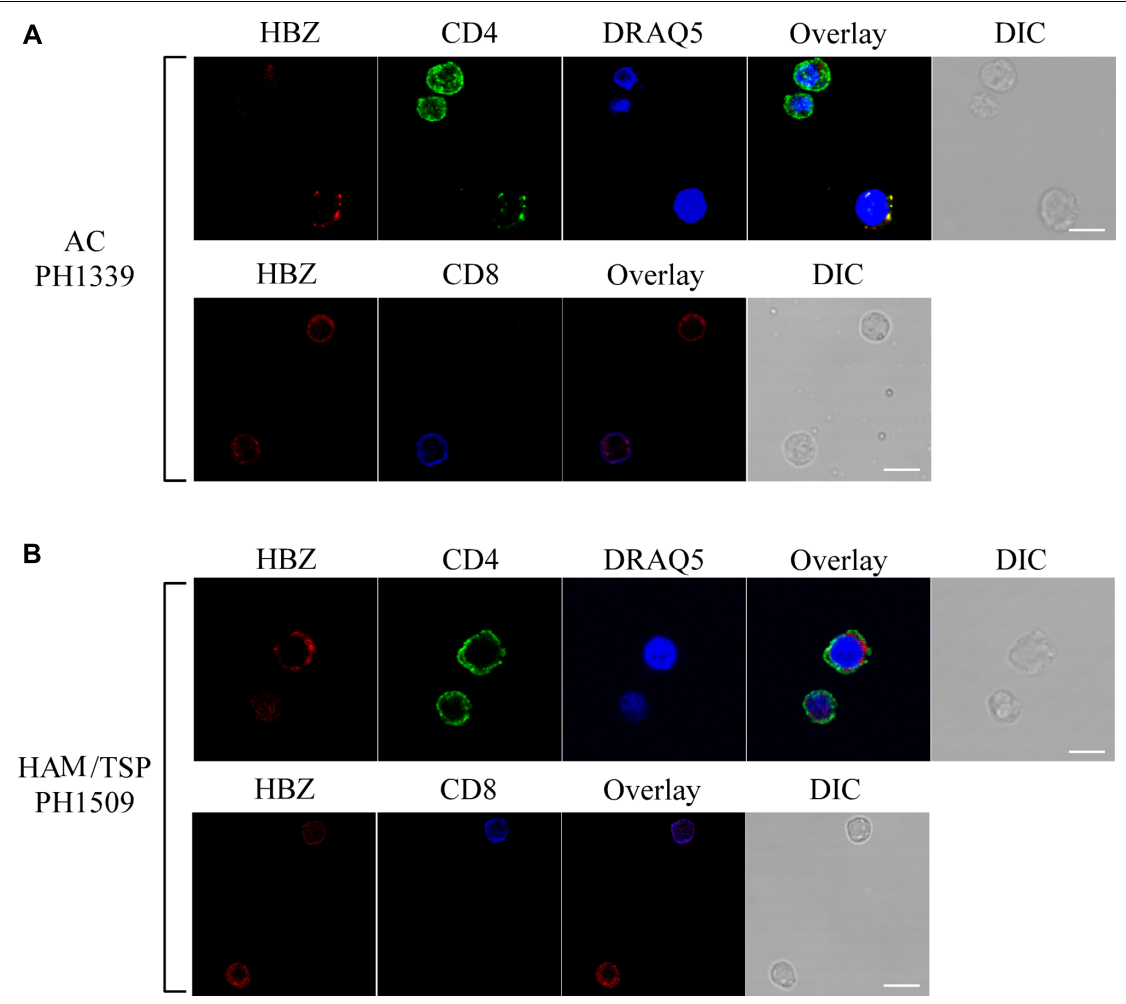

FIGURE 6 | HBZ is preferentially expressed in CD4+ T cells of AC PH1339 and HAM/TSP patient PH1509. Confocal microscopy analysis of PBMCs from AC patient PH1339 and HAM/TSP patient PH1509. (A) Upper panels: PBMC of patient AC PH1339 were co-stained with the 4D4-F3 anti-HBZ mAb followed by Alexa Fluor 546-conjugated goat anti-mouse lgG1 antibody (red) and with the anti-CD4 mAb followed by Alexa Fluor 488-conjugated goat-anti-rabbit lgG antibody (green). Lower panels: co-staining with the 4D4-F3 anti-HBZ mAb followed by Alexa Fluor 546-conjugated goat anti-mouse lgG1 antibody (red) and with the anti-CD8 rabbit mAb directly conjugated to Alexa Fluor 647 (blue). (B) PBMCs of patient HAM/TSP PH1509 were co-stained with 4D4-F3 anti-HBZ mAb and either anti-CD4 mAb (upper panels) or anti-CD8 mAb (lower panels) followed by specific secondary antibodies staining as described in panel (A). DIC represents the differential interference contrast image. At least 200 cells were analyzed; representative images derived from each sample are shown. All scale bars are $5 \mu \mathrm{m}$.

molecule involved in thymocyte selection and $\mathrm{T}$ cell receptor (TCR) signaling.

To assess whether HBZ colocalizes with THEMIS in PBMCs, we analyzed by immunofluorescence and confocal microscopy the expression and subcellular localization of both HBZ and THEMIS in PBMCs of AC and HAM/TSP patients. Figure 7 shows the results obtained in PBMCs of PH1307 and PH1419, representative of an AC and a HAM/TSP patient, respectively. As control, PBMCs from non-infected individuals were also analyzed. As expected, in PBMCs of a healthy donor, THEMIS was expressed in the cytoplasm of a discrete percentage of cells (Figure 7, PBMC, Themis). The co-staining with DRAQ5 nuclear marker confirmed THEMIS as a cytoplasmic resident protein (Figure 7, PBMC, overlay).

Interestingly, in PBMCs of PH1307 AC, coexpression of HBZ and THEMIS could be found in cells expressing both proteins at low level (Figure 7, AC PH1307, bottom panels). On the other hand, highly expressing THEMIS-positive cells (Figure 7, AC PH1307, top panels, Themis) usually did not show coexpression of HBZ (Figure 7, AC PH1307, top panels, THEMIS and overlay). Similarly, highly expressing HBZ cells can be found that do not express THEMIS (Figure 7, AC PH1307, top panels, HBZ and overlay).
Unlike AC, in PBMCs of HAM/TSP patient PH1419, the majority of HBZ-positive cells (Figure 7, HAM/TSP PH1419, top and middle panels, HBZ) were included in the highly expressing THEMIS (Figure 7, HAM/TSP PH1419, top and middle panels, Themis) and the two proteins partially colocalized in the cytoplasm (Figure 7, HAM/TSP PH1419, top and middle panels, overlay). Nevertheless, we found cells expressing either THEMIS or HBZ alone (Figure 7, HAM/TSP PH1419, bottom panels). Collectively, these findings suggest that colocalization of HBZ and THEMIS is observed, but the cytoplasmic expression of THEMIS is not required for the cytoplasmic expression of HBZ, particularly in HAM/TSP patients.

\section{An IL-2-Dependent Cell Line From a HAM/TSP Patient Further Demonstrates HBZ as a Cytoplasmic Protein Unable to Shuttle Between Cytoplasm and Nucleus}

As shown above, HBZ expression in HTLV-1-infected asymptomatic patients shows a cytoplasmic localization that is further increased both in intensity and in number of positive cells in HAM/TSP patients. To further investigate the biological basis of this peculiar subcellular distribution of HBZ compared 


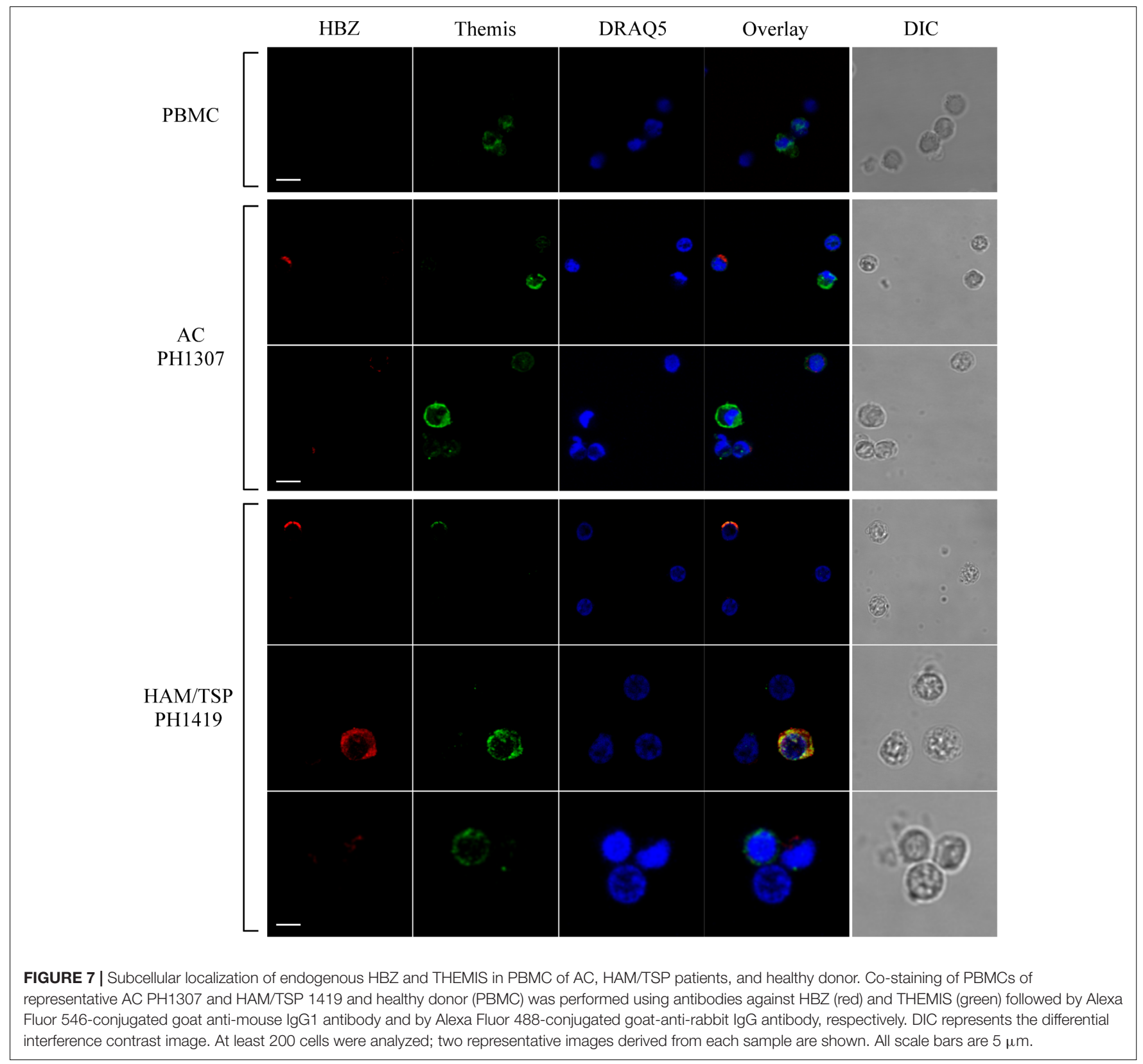

with the prominent nuclear localization found in ATL cells, we took advantage of an IL-2-dependent HTLV-1-immortalized $\mathrm{T}$ cell line, designated CB-CD4/HTLV-1 established from a HAM/TSP patient (Ozden et al., 2004). Interestingly, the cell surface phenotype of CB-CD4/HTLV-1 showed that these cells express CD4, CD25, and HLA-II markers (Figure 8, upper panels) but lack the cell surface expression of CD3. Absence of CD3 expression in HTLV-1-infected cells is not unprecedented since it has been observed also in other cell lines (Raval et al., 2015). As observed in fresh PBMCs of HAM/TSP patients, HBZ was found to be localized in the cytoplasm of CB-CD4/HTLV-1 cells (Figure 9A, HBZ). Parallel staining with DRAQ5 or with vimentin confirmed the exclusive $\mathrm{HBZ}$ cytoplasmic localization with a similar speckle-like distribution as the one observed in PBMCs of HAM/TSP patients (Figure 9A, overlay). While virtually all cells expressed $\mathrm{HBZ}$, only $20 \%$ of them expressed Tax-1. Interestingly, Tax-1 was mainly localized in the cytoplasm with a dotted-like distribution (Figure 9B, Tax-1). Parallel staining with DRAQ5 and vimentin revealed that Tax-1 is concentrated in a specific cytoplasmic area (Figure 9B, overlay). Furthermore, we observed that Tax-1 distribution did not overlap with that of HBZ, suggesting that the two proteins localized in different regions of the cytoplasmic compartment (Figure 9C, overlay). Altogether these localization studies suggested that $\mathrm{HBZ}$ resided exclusively in the cytoplasm of CB-CD4/HTLV-1 cells. To further confirm the cytoplasmic localization of HBZ, nuclear and cytoplasmic fractions of CB-CD4/HTLV-1 cells were immunoprecipitated with the 4D4-F3 anti-HBZ mAb, 


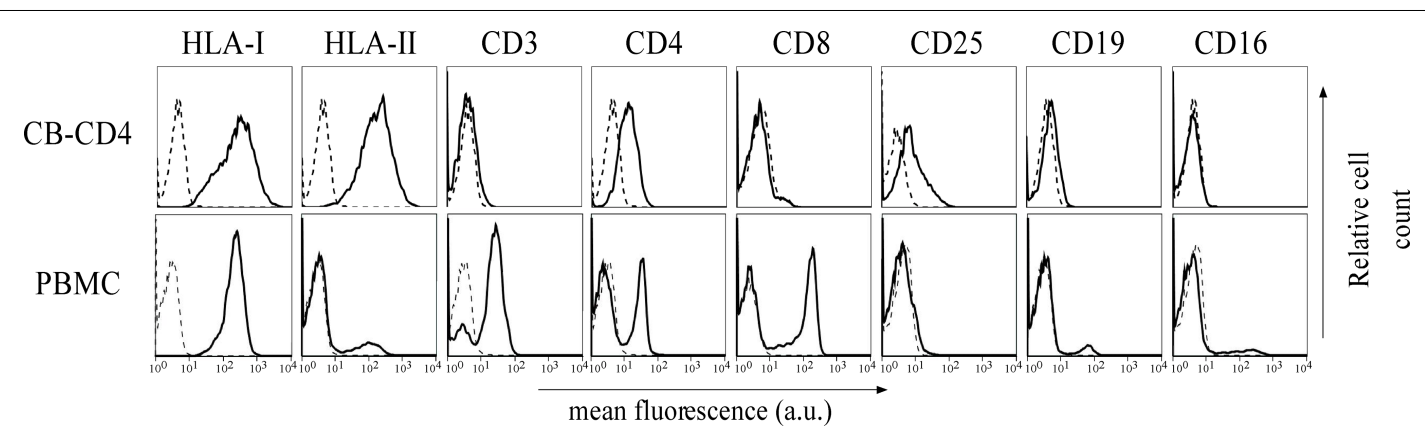

FIGURE 8 | Expression of cell surface markers in the CB-CD4/HTLV-1 cell line. The expression of HLA class I, HLA class II DR, CD3, CD4, CD8, CD25, CD19, and CD16 surface molecules on CB-CD4 HAM/TSP cells and healthy control was assessed by immunofluorescence and flow cytometry with antibodies specific for the markers indicated on the top of the panels. Results are expressed as relative number of cells (ordinate) versus the mean intensity of fluorescence in arbitrary units (abscissa). In each histogram, negative controls, obtained by staining the cells with an appropriate isotype-matched antibody, are depicted as a dashed line.

with the resulting immunoprecipitate run in SDS-PAGE and analyzed by Western blotting with the same antibody. As shown in Figure 10, HBZ protein was found only in the cytoplasmic fraction (C) of CB-CD4/HTLV-1 cells (Figure 10, IP, HBZ). Nucleoporin 98 (Nup98) and Tubulin protein expression was also analyzed (Figure 10, input) to verify the purity of nuclear $(\mathrm{N})$ and cytoplasmic (C) protein extracts. To assess whether, in CB-CD4/HTLV-1 cells, HBZ stably resides in the cytoplasm or shuttles between cytoplasm and nucleus, the cells were treated with Leptomycin B (LMB), an inhibitor of CRM-1-dependent nuclear export, and analyzed by immunofluorescence and confocal microscopy. Results clearly showed that LMB treatment did not affect HBZ cytoplasmic localization in CB-CD4/HTLV-1 $\mathrm{T}$ cells (Figure 11A, HBZ, top panel versus bottom panel). Interestingly, cytoplasmic localization of endogenous Tax-1 in CB-CD4/HTLV-1 cells was also not modified by the presence of LMB (Figure 11A, Tax-1, upper panel versus lower panel). This finding was at variance with the results observed in the Tax-1-transfected 293 T cell line in which Tax-1 was shuttling to the nucleus as assessed by a similar LMB treatment (Forlani et al., 2016a). The efficacy of LMB treatment was shown by the nuclear accumulation of p65/RelA that, in the absence of LMB treatment, was mostly localized in the cytoplasm (Figure 11B, +LMB). From these results, we conclude that in CB-CD4/HTLV-1 cells, as in HAM/TSP patients, HBZ is specifically confined to the cytoplasm and does not translocate to the nucleus.

\section{DISCUSSION}

Although many advances have been obtained on the molecular and cellular mechanisms underlining the pathogenesis of infection by HTLV-1, the first described human oncogenic retrovirus (Poiesz et al., 1980), the intimate mechanisms associated to the onset of the two major diseases associated to HTLV-1 infection, namely, acute T cell leukemia-lymphoma (ATL) and tropical spastic paraparesis (HAM/TSP), are still not fully understood. In particular, the reason why some HTLV-1infected patients develop HAM/TSP and others progress toward the neoplastic state is largely elusive.
Two viral products, Tax-1 and HBZ, are certainly involved in the pathogenesis of ATL but most likely with distinct mechanism. Tax-1 is thought to be more important in the triggering than in the maintenance of oncogenic transformation for various actions on the homeostasis of the cell initially infected by HTLV-1, particularly in the constitutive activation of the NF-kB pathway (Grassmann et al., 2005). Indeed, Tax-1 expression is not present in $40 \%$ of leukemic patients (Takeda et al., 2004). On the other hand, HBZ is persistently present in ATL and thus it is believed to play a major role in the maintenance of a neoplastic process (Matsuoka and Jeang, 2011). This is further complicated by the observation that Tax-1 and HBZ seem to have several opposing functions on specific cellular pathways involved in the control of cellular activation and proliferation (Matsuoka and Yasunaga, 2013). Mechanisms associated with the neuroinflammatory pathology of HAM/TSP depend on chronic activation of cellular immunity and damage induced by the immune response to the nervous system (Matsuura et al., 2010; Yamano and Sato, 2012; EnoseAkahata et al., 2017). The role of Tax-1 and HBZ seems to be less understood, at least in terms of recognition by immune cells and consequent outcome of protection versus immunopathology (Suemori et al., 2009; Macnamara et al., 2010; Hilburn et al., 2011).

All these events require a precise and more defined analysis of important parameters related to these viral proteins: their temporal expression, their relative amount of expression during the various phases of infection and related pathology, and, importantly, their relative subcellular distribution during the life history of infection and evolution toward distinct pathologies.

To address these issues, we have recently undertaken studies of expression, quantification, and subcellular distribution of HBZ that have been hampered in the past by the lack of suitable reagents to detect and quantify the endogenous viral protein. We have recently demonstrated for the first time that HBZ protein, previously believed as an exclusive nuclear protein, is indeed expressed in the cytoplasm of PBMCs of HAM/TSP patients (Baratella et al., 2017b), in contrast with the predominant nuclear expression in ATL cells (Raval et al., 2015). No careful studies have been reported on the expression of HBZ protein in AC. 


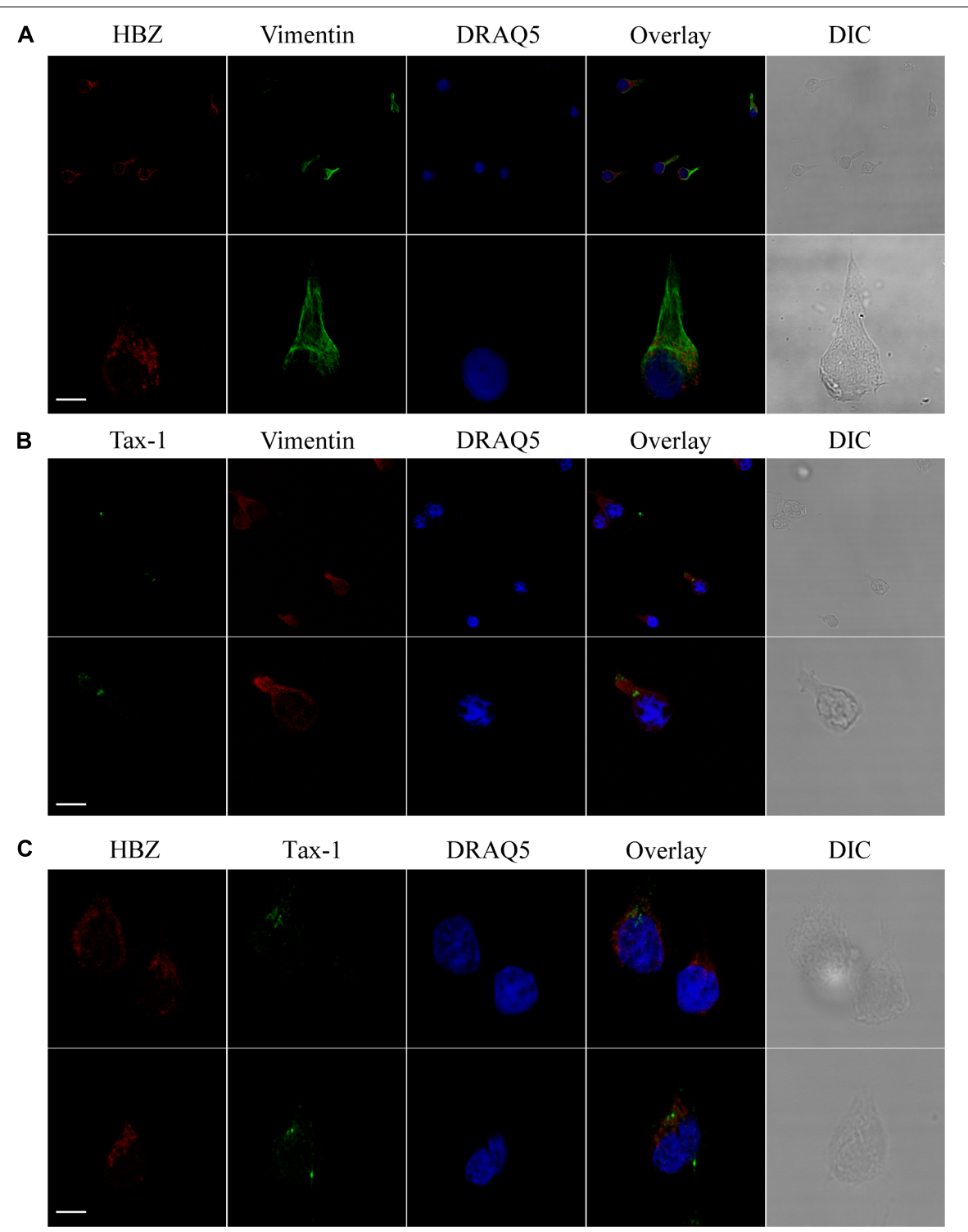

FIGURE 9 | In CB-CD4/HTLV-1 cells, HBZ and Tax-1 reside in different compartments of the cytoplasm. (A) CB-CD4/HTLV-1 cells were stained with the 4D4-F3 anti-HBZ mAb followed by Alexa Fluor 546-conjugated goat anti-mouse lgG1 antibody (red), with DRAQ5 to detect the nucleus (blue) and with anti-vimentin rabbit polyclonal antibody followed by goat anti-rabbit IgG conjugated to Alexa Fluor 488 (green) to detect the cytoplasmic compartment. DIC represents the differential interference contrast image. Three representative images for HBZ staining are shown. (B) CB-CD4/HTLV-1 cells were stained with the A51-2 anti-Tax-1 mAb followed by Alexa Fluor 488-conjugated goat-anti-mouse lgG2a antibody (green), with DRAQ5 to detect the nucleus (blue) and with anti-vimentin rabbit polyclonal antibody followed by goat anti-rabbit IgG conjugated to Alexa Fluor 546 (red) to detect the cytoplasmic compartment. DIC represents the differential interference contrast image. Two representative images for Tax-1 staining are shown. (C) CB-CD4/HTLV-1 T cells were co-stained with the 4D4-F3 anti-HBZ mAb followed by Alexa Fluor 546-conjugated goat anti-mouse lgG1 antibody (red) and with the A51-2 anti-Tax-1 mAb followed by Alexa Fluor 488-conjugated goat-anti-mouse IgG2a antibody (green) and analyzed by confocal microscopy. DRAQ5 was used to detect the nucleus. DIC represents the differential interference contrast image. Two representative images are shown. All scale bars are $5 \mu \mathrm{m}$.

Here, we have analyzed in detail the expression and subcellular distribution of $\mathrm{HBZ}$ and Tax in a cohort of AC and HAM/TSP patients. Several important findings were observed.

The confocal microscopy analysis performed on PBMCs of AC showed that HBZ protein expression could be detected in these cells, although not in all infected individuals and at a reduced number as compared to HAM/TSP. Most importantly, we show for the first time that in AC, $\mathrm{HBZ}$ is localized exclusively in the cytoplasm.

Cytoplasmic HBZ appears to be distributed in dots resembling the nuclear dots found in ATL cells. Thus, in the natural history HTLV-1 infection, expression of HBZ protein is primarily confined to the cytoplasm and, depending on the differential progression toward HTLV-1-associated diseases, HBZ remains cytoplasmic in HAM/TSP patients. Importantly, the increase in 


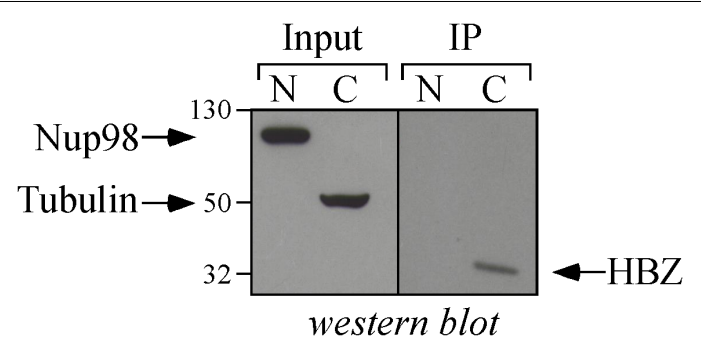

FIGURE 10 | Biochemical assessment of the cytoplasmic localization of HBZ in CB-CD4/HTLV-1 cells. Nuclear (N) and cytoplasmic (C) protein extracts obtained from CB-CD4/HTLV-1 cells $\left(8 \times 10^{6}\right.$ cells) were immunoprecipitated with an anti-HBZ 4D4-F3 mAb (IP) and analyzed for the presence of HBZ by Western blotting using the same antibody (HBZ). Ten percent of the nuclear and cytoplasmic protein extracts were analyzed for the expression of Nucleoporin 98 (NUP98) and $\beta$-tubulin (Tubulin) by Western blotting (input).

HTLV-1 PVL in these patients is paralleled by the increase in the number of HBZ-positive cells. By contrast, HBZ expression is more associated with the nucleus of ATL patients (Raval et al., 2015), strongly suggesting that the evolution of HTLV-1 infection toward the leukemic state is marked by the migration of HBZ to the nucleus. Within this context, recent studies have reported that HBZ-transfected cell lines, including the $\mathrm{T}$ cell line Jurkat, may partially segregate HBZ in the cytoplasm as a result of interaction with THEMIS (Kinosada et al., 2017), a protein expressed exclusively in $\mathrm{T}$ cells (Brockmeyer et al., 2011; Fu et al., 2013). However, confocal microscopy analysis of PBMCs of AC and HAM/TSP patients described in this paper shows that the expression of THEMIS is not necessary for the expression and cytoplasmic localization of endogenous HBZ. Thus, whether the distinct subcellular localization of HBZ observed in ATL as compared to AC and HAM/TSP is due to an active migration of $\mathrm{HBZ}$ to the nucleus or to a passive translocation due to the loss or altered expression of THEMIS remains to be elucidated. This does not exclude the idea that different cytoplasmic anchoring molecules or molecular complexes may also be involved in the cytoplasmic localization of HBZ in AC and in HAM/TSP patients (see also discussion below).

In PBMCs of AC, the Tax-1 protein was expressed in a discrete number of cells and preferentially localized in the cytoplasm. Interestingly, the expression of Tax-1 was found to be largely uncoupled to that of $\mathrm{HBZ}$, and in this respect, these findings were similar to those previously reported for HAM/TSP patients (Baratella et al., 2017b). The biological basis of the mutually exclusive expression of either HBZ or Tax-1 in the same cell in

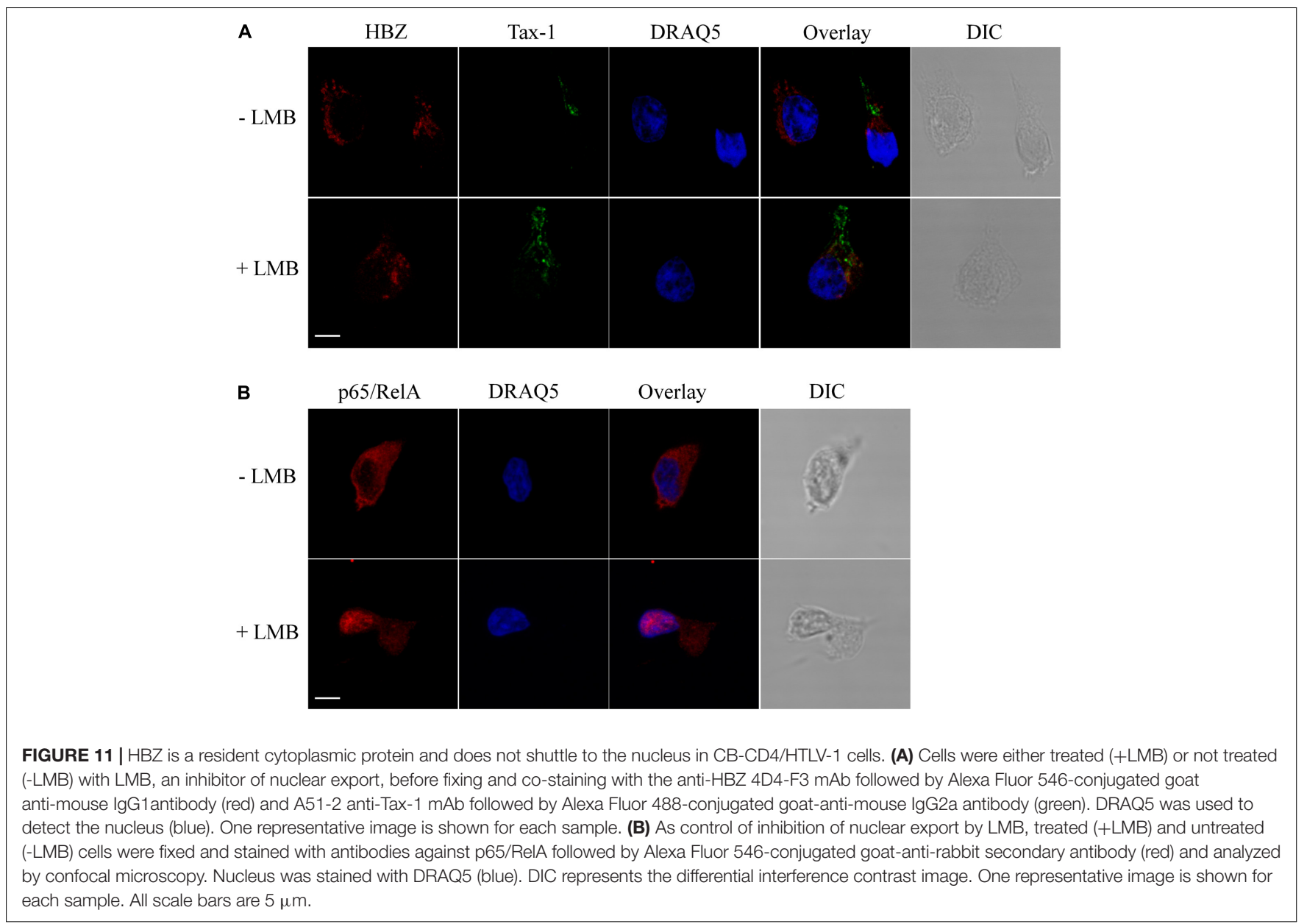


AC and HAM/TSP patients is still unknown and certainly will be the focus of our future investigation.

In this study, we have significantly expanded the number of HAM/TSP patients. We confirmed that HBZ is a cytoplasmic protein, and we showed for the first time that it is expressed in a higher number of PBMCs as compared to AC. This was paralleled by a similar higher number of PBMCs expressing Tax1 , and, as mentioned above, the increase in number of cells expressing HBZ and Tax-1 correlated often, but not always, with the higher PVL found in these patients. A noticeable exception was the $\mathrm{PH} 2116$ AC displaying a very high PVL (19.16) and only 2 and $0 \%$ of HBZ and Tax-1 positive cells, respectively. Of interest is the observation that this $\mathrm{AC}$ with an uncommonly high PVL was the spouse of a HAM/TSP patient and is clinically being followed for any signs and symptoms of neurological disease.

In line with our previous findings (Baratella et al., 2017a,b), additional confocal microscopy analysis of PBMCs of AC and HAM/TSP patients clearly showed that the major, if not the exclusive, $\mathrm{HBZ}+$ cell subpopulation was represented by CD4+ cells. Conversely, only a very limited number of HBZ-positive cells were found in the CD8 $+\mathrm{T}$ cell compartment, reinforcing the idea that in HAM/TSP as well as in AC, CD8+ $\mathrm{T}$ cell subpopulation is not a primary target of the HTLV-1 virus.

Although CD4+/CD25+ Tregs can be infected by HTLV-1 and HAM/TSP patients have been shown to have a high number of CD4+/CD25+ Tregs with impaired function and higher HBZ mRNA levels (Araya et al., 2011; Enose-Akahata et al., 2018), the results presented here indicate that in HAM/TSP patients, $\mathrm{HBZ}$ protein can be detected in CD4 $+\mathrm{T}$ cells not displaying the classical phenotype of Treg cells. Thus, the possible uncoupling of HBZ mRNA and protein expression in CD4+CD25+ Tregs as well as in other $\mathrm{CD} 4+\mathrm{T}$ cell subpopulations in both $\mathrm{AC}$ and HAM/TSP patients (Yamano et al., 2009; Leal et al., 2013; Araya et al., 2014; Billman et al., 2017) certainly requires further investigation.

Further studies by confocal and biochemical analysis conducted on CB-CD4/HTLV-1, a T cell line established from an HAM/TSP patient (Ozden et al., 2004), confirmed that HBZ

\section{REFERENCES}

Araya, N., Sato, T., Ando, H., Tomaru, U., Yoshida, M., ColerReilly, A., et al. (2014). HTLV-1 induces a Th1-like state in $\mathrm{CD}^{+}{ }^{\mathrm{CCR}} 4^{+} \mathrm{T}$ cells. J. Clin. Inv. 124, 3431-3442. doi: 10.1172/JCI 75250

Araya, N., Sato, T., Yagishita, N., Ando, H., Utsunomiya, A., Jacobson, S., et al. (2011). Human T-lymphotropic virus type 1 (HTLV-1) and regulatory T cells in HTLV-1-associated neuroinflammatory disease. Viruses 3, 1532-1548. doi: 10.3390/v3091532

Bangham, C. R. M., Cook, L. B., and Melamed, A. (2014). HTLV-1 clonality in adult T-cell leukaemia and non-malignant HTLV-1 infection. Semin. Cancer Biol. 26, 89-98. doi: 10.1016/j.semcancer.2013.11.003

Baratella, M., Forlani, G., and Accolla, R. S. (2017a). HTLV-1 HBZ viral protein: a key player in HTLV-1 mediated diseases. Front. Microbiol. 8:2615. doi: 10.3389/ fmicb.2017.02615

Baratella, M., Forlani, G., Raval, G. U., Tedeschi, A., Gout, O., Gessain, A., et al. (2017b). Cytoplasmic localization of HTLV-1 HBZ protein: a biomarker of HTLV-1-associated myelopathy/tropical spastic paraparesis protein resides exclusively in the cytoplasm. Tax-1, expressed in $20 \%$ of CB-CD4/HTLV-1 cells, also localized mostly in the cytoplasm. The CB-CD4/HTLV-1 cell line was instrumental to unambiguously show that $\mathrm{HBZ}$ does not shuttle between the cytoplasm and nucleus at least in a CRM1-dependent manner as assessed by LMB treatment. These data, along with previous data from our group (Baratella et al., 2017b), give support to the idea that in AC and in HAM/TSP patients, HBZ may be actively retained in the cytoplasm (Baratella et al., 2017a).

In conclusion, we believe that the data presented in this research add new relevant information for a better definition of the pathological states associated with HTLV-1 infection, particularly in relation to the distinct subcellular expression of $\mathrm{HBZ}$ in the different pathological contests and related pathologies. Whether HBZ cytoplasmic and nuclear localization in the natural history of HTLV-1 infection represents a marker of infection or is part of the mechanism governing the evolution toward HAM/TSP or ATL is the challenge for future investigation.

\section{AUTHOR CONTRIBUTIONS}

GF, MB, and RA conceived the work. GF, MB, and AT performed the experiments. All authors wrote, revised, and approved the final manuscript.

\section{FUNDING}

This research was supported by University of Insubria "FAR 2016 and 2017" (to RA and GF); by The Institutional Grant 2017, University of Insubria, to RA; and in part by European Community FP7 Grant no. 602893 "Cancer Vaccine Development for Hepatocellular Carcinoma-HepaVAC” http: //www.hepavac.eu (to RA and GF). This research was also supported in part by the Intramural Research Program of the NINDS, NIH to SJ. The support of the NIH inpatient and outpatient neurology staff is acknowledged.

(HAM/TSP). PLoS Negl. Trop. Dis. 11:e0005285. doi: 10.1371/journal.pntd.000 5285

Billman, M. R., Rueda, D., and Bangham, C. R. M. (2017). Single-cell heterogeneity and cell-cycle-related viral gene bursts in the human leukaemia virus HTLV-1. Wellcom. Open Res. 2:87. doi: 10.12688/wellcomeopenres. 12469.2

Brockmeyer, C., Paster, W., Pepper, D., Tan, C. P., Trudgian, D. C., McGowan, S., et al. (2011). T cell receptor (TCR)-induced tyrosine phosphorylation dynamics identifies THEMIS as a new TCR signalosome component. J. Biol. Chem. 286, 7535-7547. doi: 10.3390/v3091532

Brunetto, G. S., Massoud, R., Leibovitch, E. C., Caruso, B., Johnson, K., Ohayon, J., et al. (2014). Digital droplet PCR (ddPCR) for the precise quantification of human T-lymphotropic virus 1 PVLs in peripheral blood and cerebrospinal fluid of HAM/TSP patients and identification of viral mutations. J. Neurovirol., 20, 341-351. doi: 10.1007/s13365-014-0249-3.

Cavanagh, M.-H., Landry, S., Audet, B., Arpin-André, C., Hivin, P., Paré, M.E., et al. (2006). HTLV-I antisense transcripts initiating in the 3'LTR are alternatively spliced and polyadenylated. Retrovirology $3: 15$. doi: 10.1186/17424690-3- 15 
Enose-Akahata, Y., Abrams, A., Massoud, R., Bialuk, I., Johnson, K. R., Green, P. L., et al. (2013). Humoral immune response to HTLV-1 basic leucine zipper factor (HBZ) in HTLV-1-infected individuals. Retrovirology 10:19. doi: 10.1186/17424690-10-19

Enose-Akahata, Y., Azodi, S., Smith, B. R., Billioux, B. J., Vellucci, A., Ngouth, N., et al. (2018). Immunophenotypic characterization of CSF B cells in virusassociated neuroinflammatory diseases. PLoS Pathog. 14:e1007042. doi: 10. 1371/journal.ppat.1007042

Enose-Akahata, Y., Vellucci, A., and Jacobson, S. (2017). Role of HTLV-1 Tax and HBZ in the pathogenesis of HAM/TSP. Front. Microbiol. 8:2563. doi: 10.3389/ fmicb.2017.02563

Forlani, G., Abdallah, R., Accolla, R. S., and Tosi, G. (2013). The MHC-II transactivator CIITA, a restriction factor against oncogenic HTLV-1 and HTLV2 retroviruses: similarities and differences in the inhibition of Tax-1 and Tax-2 viral transactivators. Front. Microbiol. 4:234. doi: 10.3389/fmicb.2013.00234

Forlani, G., Abdallah, R., Accolla, R. S., and Tosi, G. (2016a). The major histocompatibility complex class II transactivator CIITA inhibits the persistent activation of NF- $\kappa \mathrm{B}$ by the human $\mathrm{T}$ cell lymphotropic virus type 1 Tax-1 oncoprotein. J. Virol. 90, 3708-3721. doi: 10.1128/JVI.03000-15

Forlani, G., Turrini, F., Ghezzi, S., Tedeschi, A., Poli, G., Accolla, R. S., et al. (2016b). The MHC-II transactivator CIITA inhibits Tat function and HIV-1 replication in human myeloid cells. J. Transl. Med. 14:94. doi: 10.1186/s12967016-0853-5

Fu, G., Casas, J., Rigaud, S., Rybakin, V., Lambolez, F., Brzostek, J., et al. (2013). Themis sets the signal threshold for positive and negative selection in T-cell development. Nature 504, 441-445. doi: 10.1038/nature 12718

Gaudray, G., Gachon, F., Basbous, J., Biard-Piechaczyk, M., Devaux, C., and Mesnard, J.-M. (2002). The complementary strand of the human T-cell leukemia virus type 1 RNA genome encodes a bZIP transcription factor that down-regulates viral transcription. J. Virol. 76, 12813-12822. doi: 10.1128/JVI. 76.24.12813-12822.2002

Gessain, A., and Cassar, O. (2012). Epidemiological aspects and world distribution of HTLV-1 infection. Front. Microbiol. 3:388. doi: 10.3389/fmicb.2012. 00388

Gessain, A., Vernant, J. C., Maurs, L., Barin, F., Gout, O., Calender, A., et al. (1985). Antibodies to human T-lymphotropic virus type-1 in patients with tropical spastic paraparesis. Lancet 326, 407-410. doi: 10.1016/S0140-6736(85)92734-5

Grassmann, R., Aboud, M., and Jeang, K.-T. (2005). Molecular mechanisms of cellular transformation by HTLV-1 Tax. Oncogene 24, 5976-5985. doi: 10.1038/ sj.onc. 1208978

Hilburn, S., Rowan, A., Demontis, M.-A., MacNamara, A., Asquith, B., Bangham, C. R. M., et al. (2011). In vivo expression of human T-lymphotropic virus type 1 basic leucine-zipper protein generates specific CD8+ and CD4+ T-lymphocyte responses that correlate with clinical outcome. J. Infect. Dis. 203, 529-536. doi: 10.1093/infdis/jiq078

Hivin, P., Frédéric, M., Arpin-André, C., Basbous, J., Gay, B., Thébault, S., et al. (2005). Nuclear localization of HTLV-I bZIP factor (HBZ) is mediated by three distinct motifs. J. Cell Sci. 118, 1355-1362. doi: 10.1242/jcs.01727

Igakura, T., Stinchcombe, J. C., Goon, P. K. C., Taylor, G. P., Weber, J. N., Griffiths, G. M., et al. (2003). Spread of HTLV-I between lymphocytes by virus-induced polarization of the cytoskeleton. Science 299, 1713-1716. doi: 10.1126/science. 1080115

Kinosada, H., Yasunaga, J.-I., Shimura, K., Miyazato, P., Onishi, C., Iyoda, T., et al. (2017). HTLV-1 bZIP factor enhances T-cell proliferation by impeding the suppressive signaling of co-inhibitory receptors. PLoS Pathog. 13:e1006120. doi: 10.1371/journal.ppat.1006120

Larocca, D., Chao, L. A., Seto, M. H., and Brunck, T. K. (1989). Human T-cell leukemia virus minus strand transcription in infected T-cells. Biochem. Biophys. Res. Commun. 163, 1006-1013. doi: 10.1016/0006-291X(89)92322-X

Leal, F. E., Ndhlovu, L. C., Hasenkrug, A. M., Bruno, F. R., Carvalho, K. L., WynnWilliams, H., et al. (2013). Expansion in CD39 ${ }^{+} \mathrm{CD} 4^{+}$immunoregulatory T cells and rarity of Th17 cells in HTLV-1 infected patients is associated with neurological complications. PLoS Negl. Trop. Dis. 7:e2028. doi: 10.1371/journal. pntd.0002028

Li, H.-C., Biggar, R. J., Miley, W. J., Maloney, E. M., Cranston, B., Hanchard, B., et al. (2004). Provirus load in breast milk and risk of mother-to-child transmission of human T lymphotropic virus type I. J. Infect. Dis. 190, 1275 1278. doi: $10.1086 / 423941$

Ma, G., Yasunaga, J.-I., and Matsuoka, M. (2016). Multifaceted functions and roles of HBZ in HTLV-1 pathogenesis. Retrovirology 13:16. doi: 10.1186/s12977-0160249-x

Macnamara, A., Rowan, A., Hilburn, S., Kadolsky, U., Fujiwara, H., Suemori, K., et al. (2010). HLA class I binding of HBZ determines outcome in HTLV-1 infection. PLoS Pathog. 6:e1001117. doi: 10.1371/journal.ppat.1001117

Matsuoka, M., and Jeang, K.-T. (2007). Human T-cell leukaemia virus type 1 (HTLV-1) infectivity and cellular transformation. Nat. Rev. Cancer 7, 270-280. doi: $10.1038 / \mathrm{nrc} 2111$

Matsuoka, M., and Jeang, K. T. (2011). Human T-cell leukemia virus type 1 (HTLV-1) and leukemic transformation: viral infectivity, Tax, HBZ and therapy. Oncogene 30, 1379-1389. doi: 10.1038/onc.2010.537

Matsuoka, M., and Yasunaga, J.-I. (2013). Human T-cell leukemia virus type 1: replication, proliferation and propagation by Tax and HTLV-1 bZIP factor. Curr. Opin. Virol. 3, 684-691. doi: 10.1016/j.coviro.2013.08.010

Matsuura, E., Yamano, Y., and Jacobson, S. (2010). Neuroimmunity of HTLV-I infection. J. Neuroimmune Pharmacol. 5, 310-325. doi: 10.1007/s11481-0109216-9

Mitobe, Y., Yasunaga, J.-I., Furuta, R., and Matsuoka, M. (2015). HTLV-1 bZIP factor RNA and protein impart distinct functions on T-cell proliferation and survival. Cancer Res. 75, 4143-4152. doi: 10.1158/0008-5472.can15-0942

Mukai, R., and Ohshima, T. (2011). HTLV-1 HBZ activates mTOR signaling pathway via inhibition of GADD34. Retrovirology 8:A155. doi: 10.1186/17424690-8-S1-A155

Murata, K., Hayashibara, T., Sugahara, K., Uemura, A., Yamaguchi, T., Harasawa, H., et al. (2006). A novel alternative splicing isoform of human T-cell leukemia virus type 1 bZIP factor (HBZ-SI) targets distinct subnuclear localization. J. Virol. 80, 2495-2505. doi: 10.1128/JVI.80.5.2495-2505.2006

Osame, M., Usuku, K., Izumo, S., Ijichi, N., Amitani, H., Igata, A., et al. (1986). HTLV-I associated myelopathy, a new clinical entity. Lancet 327, 1031-1032. doi: 10.1016/S0140-6736(86)91298-5

Ozden, S., Cochet, M., Mikol, J., Teixeira, A., Gessain, A., and Pique, C. (2004). Direct evidence for a chronic CD8+-T-cell-mediated immune reaction to tax within the muscle of a human T-cell leukemia/lymphoma virus type 1-infected patient with sporadic inclusion body myositis. J. Virol. 78, 10320-10327. doi: 10.1128/JVI.78.19.10320-10327.2004

Pais-Correia, A.-M., Sachse, M., Guadagnini, S., Robbiati, V., Lasserre, R., Gessain, A., et al. (2009). Biofilm-like extracellular viral assemblies mediate HTLV-1 cellto-cell transmission at virological synapses. Nat. Med. 16, 83-89. doi: 10.1038/ nm.2065

Pique, C., and Jones, K. S. (2012). Pathways of cell-cell transmission of HTLV-1. Front. Microbiol. 3:378. doi: 10.3389/fmicb.2012.00378

Poiesz, B. J., Ruscetti, F. W., Gazdar, A. F., Bunn, P. A., Minna, J. D., and Gallo, R. C. (1980). Detection and isolation of type C retrovirus particles from fresh and cultured lymphocytes of a patient with cutaneous T-cell lymphoma. Proc. Natl. Acad. Sci. U.S.A. 77, 7415-7419. doi: 10.1073/pnas.77.12.7415

Raval, G. U., Bidoia, C., Forlani, G., Tosi, G., Gessain, A., and Accolla, R. S. (2015). Localization, quantification and interaction with host factors of endogenous HTLV-1 HBZ protein in infected cells and ATL. Retrovirology 12:59. doi: 10. 1186/s12977-015-0186-0

Satou, Y., Yasunaga, J.-I., Yoshida, M., and Matsuoka, M. (2006). HTLV-I basic leucine zipper factor gene mRNA supports proliferation of adult $\mathrm{T}$ cell leukemia cells. Proc. Natl. Acad. Sci. U.S.A. 103, 720-725. doi: 10.1073/pnas.0507631103

Shiohama, Y., Naito, T., Matsuzaki, T., Tanaka, R., Tomoyose, T., Takashima, H., et al. (2016). Absolute quantification of HTLV-1 basic leucine zipper factor (HBZ) protein and its plasma antibody in HTLV-1 infected individuals with different clinical status. Retrovirology 13:29. doi: 10.1186/s12977-016-0263-Z

Suemori, K., Fujiwara, H., Ochi, T., Ogawa, T., Matsuoka, M., Matsumoto, T., et al. (2009). HBZ is an immunogenic protein, but not a target antigen for human T-cell leukemia virus type 1-specific cytotoxic T lymphocytes. J. Gen. Virol. 90, 1806-1811. doi: 10.1099/vir.0.010199-0

Takeda, S., Maeda, M., Morikawa, S., Taniguchi, Y., Yasunaga, J.-I., Nosaka, K., et al. (2004). Genetic and epigenetic inactivation of tax gene in adult T-cell leukemia cells. Int. J. Cancer 109, 559-567. doi: 10.1002/ijc.20007 
Taniguchi, Y., Nosaka, K., Yasunaga, J.-I., Maeda, M., Mueller, N., Okayama, A., et al. (2005). Silencing of human T-cell leukemia virus type I gene transcription by epigenetic mechanisms. Retrovirology 2:64. doi: 10.1186/1742-4690-2-64

Tosi, G., Forlani, G., Andresen, V., Turci, M., Bertazzoni, U., Franchini, G., et al. (2011). Major histocompatibility complex class II transactivator CIITA is a viral restriction factor that targets human T-cell lymphotropic virus type 1 Tax-1 function and inhibits viral replication. J. Virol. 85, 10719-10729. doi: 10.1128/JVI.00813-11

Usui, T., Yanagihara, K., Tsukasaki, K., Murata, K., Hasegawa, H., Yamada, Y., et al. (2008). Characteristic expression of HTLV-1 basic zipper factor (HBZ) transcripts in HTLV-1 provirus-positive cells. Retrovirology 5:34. doi: 10.1186/ 1742-4690-5-34

Yamano, Y., Araya, N., Sato, T., Utsunomiya, A., Azakami, K., Hasegawa, D., et al. (2009). Abnormally high levels of virus-infected IFN- $\gamma^{+} \mathrm{CCR}^{+} \mathrm{CD}^{+} \mathrm{CD}^{+} 5^{+} \mathrm{T}$ cells in a retrovirus-associated neuroinflammatory disorder. PLos One 4:e6517. doi: 10.1371/journal.pone. 0006517
Yamano, Y., and Sato, T. (2012). Clinical pathophysiology of human T-lymphotropic virus-type 1-associated myelopathy/tropical spastic paraparesis. Front. Microbiol. 3:389. doi: 10.3389/fmicb.2012.00389

Zhao, T., and Matsuoka, M. (2012). HBZ and its roles in HTLV-1 oncogenesis. Front. Microbiol. 3:247. doi: 10.3389/fmicb.2012.00247

Conflict of Interest Statement: The authors declare that the research was conducted in the absence of any commercial or financial relationships that could be construed as a potential conflict of interest.

Copyright (c) 2019 Forlani, Baratella, Tedeschi, Pique, Jacobson and Accolla. This is an open-access article distributed under the terms of the Creative Commons Attribution License (CC BY). The use, distribution or reproduction in other forums is permitted, provided the original author(s) and the copyright owner(s) are credited and that the original publication in this journal is cited, in accordance with accepted academic practice. No use, distribution or reproduction is permitted which does not comply with these terms. 